\title{
CURRENT UNDERSTANDING OF CRITICAL GAME SCENARIOS IN TEAM SPORTS: SYSTEMATIC REVIEW
}

review paper

() Wroclaw University of Health and Sport Sciences

DOI: https://doi.org/10.5114/hm.2022.109068

\section{JOÃO B. MARTINS, ISABEL MESQUITA, ADEMILSON MENDES, LETÍCIA SANTOS, JOSÉ AFONSO}

Centre for Research, Education, Innovation and Intervention in Sport, Faculty of Sport, University of Porto, Porto, Portugal

\begin{abstract}
In sports, game scenarios can be critical or non-critical, potentially presenting very distinct implications for the game flow. However, defining a critical scenario is not an easy task. Although there is some research on game scenarios, game situations, game moments, and critical moments, through this systematic review we intend to fill a gap in the knowledge of critical scenarios in order to structure the existing knowledge and pinpoint current limitations. The search was conducted in July of 2020 in Web of Science, Scopus, PubMed, SciELO, and, through a manual search, in Google Scholar. The eligibility criteria included original research with quantitative and/or qualitative analysis of critical game scenarios or game moments. The participants were humans of any gender, age group, health status, competitive level, or expertise. Risk of bias assessment involved 14 criteria in the evaluation of the studies. The study synthesis methods followed a qualitative synthesis of the main results of each study in the final sample. Of the 279 researched articles, only 4 met the inclusion criteria, i.e. only 4 provided data concerning critical game scenarios. Their contributions are discussed in detail, as is the open research windows for the future. Overall, there is clearly a need for more research specifically addressing this topic, with a huge gap between theoretical relevance and actual investigation.
\end{abstract}

Key words: performance analysis, match analysis, game moments, critical moments

\section{Introduction}

In team sports, a scenario can be defined as a typology of play/game flow that has specific features and implications [1,2]. Game scenarios contain a set of variables and conditions that are functionally linked and represent a functional whole [3]. Consequently, it is important to categorize the distinct game scenarios as typical of each sport, since this will result in more refined information for structuring the training sessions and constitute an effective tool for performance analysis, allowing coaches to vary the focus of training and improve specific actions in a context close to the real one [4].

In systems analysis, criticality is important in investigating stress and task performance [5], being used to identify important situations and high pressure presence, mainly influenced by the temporal phase and differential score [6, 7]. Game period and score evolu- tion is the situational link of reference to which the subject and the task are inevitably linked [8]. In this context, different game scenarios may have distinct implications and, consequently, some scenarios may have a superior criticality relative to others. Unfortunately, there seems to be no widely accepted term for referring to critical game scenarios. For the most part, expressions such as game moments, critical moments, game scenarios, and others have not been properly defined in the sports sciences literature. Defining critical game scenarios can be quite subjective and influenced by many variables. Therefore, this theme may have a profound relevance in sports, providing a key tool for coaches to manipulate training sessions, e.g. to use high-pressure exercises that are representative of critical game scenarios [9].

In this vein, understanding critical game scenarios contributes to a better comprehension of the performance, as well as better preparation for exhibiting

Correspondence address: João Bernardo Martins, Faculty of Sport, University of Porto, R. Dr. Plácido da Costa 91, 4200-450 Porto, Portugal, e-mail: joao_10z@hotmail.com

Received: January 22, 2021

Accepted for publication: August 05, 2021

Citation: Martins JB, Mesquita I, Mendes A, Santos L, Afonso J. Current understanding of critical game scenarios in team sports: systematic review. Hum Mov. 2022;23(2):1-11; doi: https://doi.org/10.5114/hm.2022.109068. 
well-adjusted dynamic and self-organizational behaviours $[10,11]$. However, research seems to be focused on the analysis of concepts such game scenarios in critical and non-critical game moments [12-14]. In fact, critical moments vary depending on their intentionality, which involves the individual's experience combined with time and emotional response [14]. Conversely, a non-critical moment is understood as a response to a performance without contextual pressure [15].

While the study of critical moments is a highly relevant approach, we believe it to be a small part of the broader concept of critical game scenarios [16]. Since critical scenarios portray game-specific situations, they trigger activity in a coherent structure [17], limiting and organizing what the situation means for the subject and for the actions to be successfully carried out of the task, in this case through critical game scenarios, considered one of the performance indicators [18, 19]. Thus, critical scenarios can include: (i) critical moments (time when changes in game state or an unbalanced score occurs depending on time intervals, where these differences have a greater impact on the final outcome of the match [6]); (ii) critical situations (situations where the team is under difficult conditions) [20]) during critical or non-critical moments; and (iii) match status (e.g., winning or losing final score in matches with a small or large difference in goals scored [21]). These should be considered as they have an influence on the performance of the playing patterns of players and teams.

As a consequence of the studies developed on critical scenarios, in our opinion, there seems to be a need to hierarchize and categorize the concepts of critical scenarios and critical moments, so critical scenarios should first emerge because they can occur at a critical or non-critical time.

Studies such as those by Récopé et al. [22] and Sánchez-Moreno et al. [23] have focused on critical scenarios referring to the behaviour of teams in critical or non-critical moments. In order to analyse representations of game actions, as critical game scenarios, the model of Newell's constraints [24] is fundamental to analyse and adapt motor skills because the 3 vectors (task, environment, and individual) are among the ways to classify critical game scenarios. Thus, there is a 2-way interconnection between the model and the critical scenario, as it allows to guide decisions on the provision of appropriate instructions for development. Still, Araújo et al. [25] argued that functional patterns of coordinated behaviour emerged through performers' inter-actions with each other under specific task constraints of a competitive environment.
Therefore, critical and non-critical scenarios are relevant in the process of evolution of teams, allowing to simulate them in training and influence the competitive process [26].

The aim of this study was to identify the extent of studies on critical game scenarios and investigate their influence on individual and collective performance, associated with game patterns or game actions. The novelty of this systematic review can be divided into 2 aspects [22, 23]: (a) understanding the theme of critical game scenarios (what they represent and to how teams both influence and are influenced by those critical scenarios); (b) assessing how critical game scenarios are being investigated through the lenses of performance analysis. As previously established, critical scenarios include but are not limited to critical moments $[6,16,20]$.

\section{Material and methods}

\section{Eligibility criteria}

Articles were eligible if they were published or accepted, with full text in English. No limitations were imposed on the date of publication. The Preferred Reporting Items for Systematic Reviews and Meta-Analyses (PRISMA) guidelines were adopted. The PICOS process was established as follows: (i) the participants had to be human, regardless of sex/gender, age group, health status, competitive level, or level of expertise; (ii) all interventions using match analysis were considered critical game scenarios or game moments, with no limitations with regard to the sport; (iii) comparators were non-critical scenarios; (iv) outcomes were any effects on performance; (v) the study design was limited to original research with any type of quantitative and/or qualitative game analysis. This study was approved by the Ethics Committee at the Centre of Research, Education, Innovation and Intervention in Sport of the University of Porto (09 2020 CEFADE).

\section{Information sources and search}

Databases used for this research were: Web of Science, Scopus, PubMed, and SciELO. The search was conducted in July of 2020. The search protocol used Boolean operators and the title or abstract or keywords (in Web of Science, this combination is termed 'Topic' and also includes keywords; Scopus also includes keywords) had to contain: (i) "match scenarios" OR "game scenarios" OR "game situations" OR "game moments" OR "critical moments" OR "critical sce- 
narios"; (ii) AND differences OR variation OR variations OR distinct OR variability; (iii) AND sport OR sports OR games. No limitations were imposed on the date of publication. In Scopus, the document type filtering was limited to article. In SciELO, 2 separate searches had to be conducted: one for title and another one for abstract. Also, a manual search was performed in Google Scholar.

\section{Study selection}

The initial screening provided 277 results (91 in Web of Science, 167 in Scopus, 19 in PubMed, and 0 in SciELO). After this electronic search, we performed a manual search in Google Scholar to ensure greater robustness in the study, and 2 more studies were included $(n=279)$ The identified articles were then exported to Mendeley reference manager software (Freemium, version 1803, Elsevier, Amsterdam). After the removal of duplicates, 195 records remained that were considered eligible for further scrutiny. After the initial screening of the title and abstract, 160 articles were excluded for being outside the scope and the remaining 35 went for full-text analysis.

At this stage, 31 articles were excluded. The following were excluded because they were unrelated to the theme of this review, despite having promising titles and abstracts: Andrienko et al. [27], Bartlett et al. [28], Blomqvist et al. [29], Evans et al. [30], Rojas Ferrer et al. [31], Filipcic et al. [32], French et al. [33], GonzálezVíllora et al. [34], Klostermann et al. [35], Kokoulina et al. [36], Koo et al. [37], Lupo et al. [38], McPherson [39], Praça et al. [40], Schläppi-Lienhard and Hossner [41], Sevil Serrano et al. [42], Uljevic et al. [43], and Zubillaga et al. [44]. The following articles were eliminated because they did not present relevant data on the theme of this research: Batista et al. [13], Cañadas et al. [45], Connor et al. [46], Ferraz et al. [47], Gomez et al. [48], Gonçalves et al. [49], Lupo et al. [50], Millslagle [51], and Ramos et al. [52]. An article by Ferreira et al. [53] was eliminated because it dealt with coaches and non-athletes. Likewise, articles by Medina et al. [54], Reina et al. [55], and Pombo et al. [56] were excluded because the body of the paper was written in Portuguese or Spanish.

Thus, the final sample consisted of 4 original research papers [22, 23, 57, 58]. The data for the 4 articles are detailed in Table 1.

\section{Data collection process}

The main author conducted the initial search. One week after the initial search, 2 co-authors repeated the search to ensure the quality of this first step. All the authors reviewed the entirety of the retrieved papers to decide which ones to include and which to exclude. In cases of disagreement, the authors discussed the article in detail and re-analysed it to ensure the quality of this step.

\section{Data items}

For the papers included in the analysis, the following data items were considered: sample (e.g., athletes, sex/gender, age group in game analysis context, level of game, and experience), main methodological procedures (details of the protocols and tests), variables analysed, and main evidence.

\section{Risk of bias in individual studies and across studies}

The tool used in this investigation was the same as Clemente et al. [59] applied in their study, being an adapted version of the tool utilized by Sarmento et al. [60]. It served to evaluate the studies (with the answers of yes, no, or not applicable) with the consideration of 14 criteria: the purpose of the study (item 1), the presence of the most relevant literature (item 2), the appropriate design for the investigation (item 3), the description of the sample (item 4), the justification of the sample size (item 5), the indication of the use of informed consent (item 6), the correctness of the measures of the results (item 7), the validation of the results (item 8), the detailed description of the methods (item 9), the reporting of the results in terms of statistical importance (item 10), the adequacy of the methods of analysis (item 11), the adequacy of conclusions based on the methods (item 12), the existence of practical implications (item 13), and recognition and description of the limitations of the study (item 14). The 14 quality criteria were marked by using a binary scale (i.e. 0 or 1). However, item 6 also had an option of 'If not applicable, assume NA'. Two of the authors classified the complete articles included in the sample. The agreement consisted in the agreement of both, and the answers of each tested through the kappa coefficient $(\kappa)$ were used to measure the reliability rate between the reviewers.

\section{Ethical approval}

The conducted research is not related to either human or animal use. 


\section{HUMAN MOVEMENT}

J.B. Martins et al., Critical scenarios in team sports

\section{Results}

\section{Study selection}

The original search in the databases returned 279 articles. After 84 duplicated articles were excluded, 195 papers were screened for relevance on the basis of their title and abstract; 160 studies were excluded. Therefore, 35 articles were analysed in detail. Out of these, 31 were rejected because they did not meet the inclusion criteria. At the end of the screening procedure, only 4 articles were included for in-depth and full reading and analysis (Figure 1).

\section{Characteristics and results of individual studies}

The complete data items for individual studies can be found in Table 1 .

Récopé et al. [22] studied intra-team differences in defence-related game scenarios. They conducted 2 case studies. In the first one, the sample comprised
31 professional male volleyball players from 2 national teams, who were observed during 3 games in the World League. In the second case, the sample included 12 players $(6$ representatives of population $\mathrm{A}$ and $B$ each, composed of a selection of 3 members of each national team). These case studies developed a systematic observation of the behaviour of players in specific defensive situations. The main evidence was: (1) the existence of differences between groups of highlevel volleyball players in the defensive context; (2) the identification of a specific overall coherence that guides and organizes a defensive activity. We highlight that in this study, the time pressure, the evaluation of the situation, and the way of performing the actions are highly connected, but also organized and guided by the subconscious sense of the athlete.

Sánchez-Moreno et al. [23] analysed how the length of the rally affected the performance in accordance with the final action of the rally and the level of play, as well as identified potential critical rallies associated with the length of the rally in men's volleyball. In

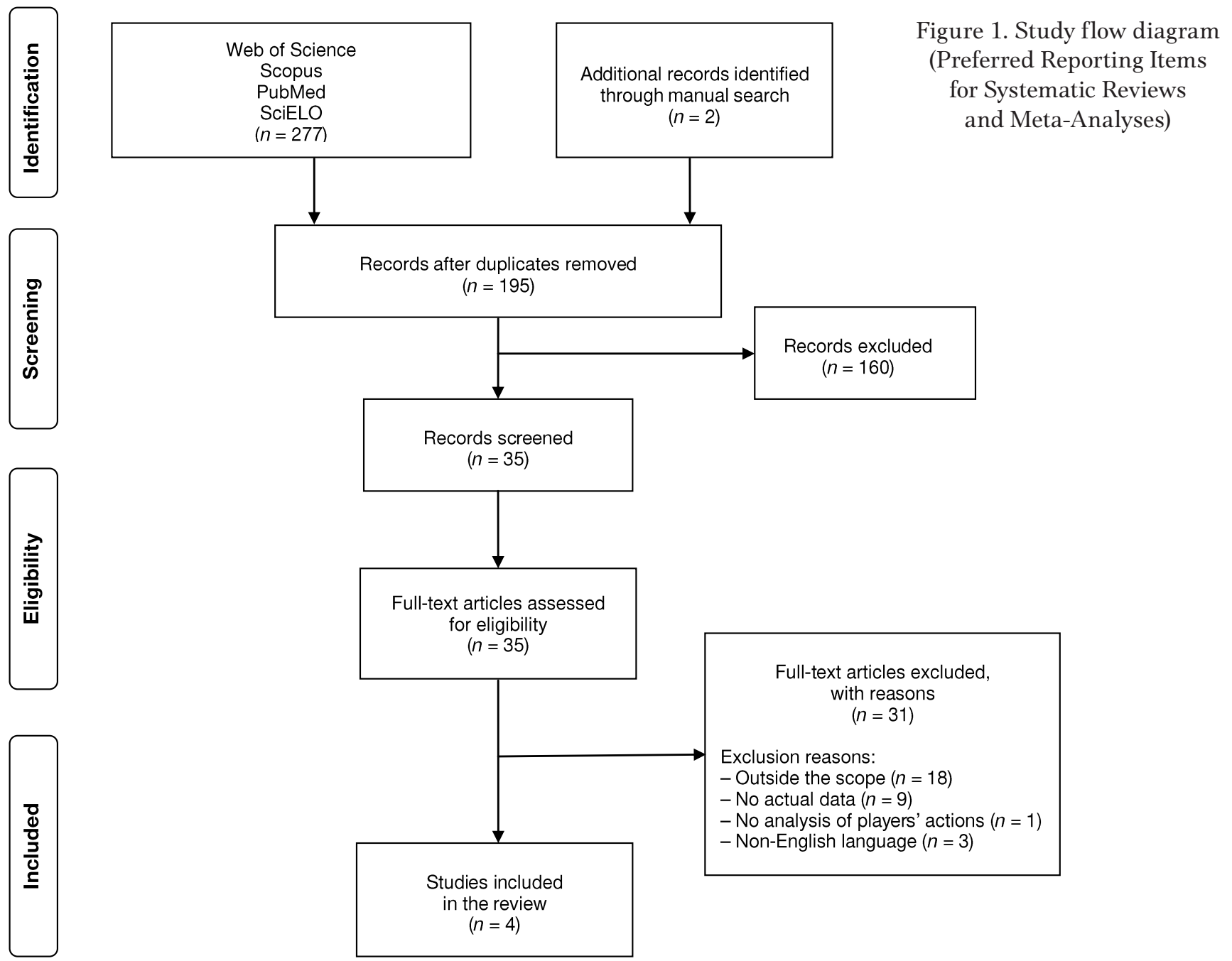


Table 1. Data items for the individual studies

\begin{tabular}{|c|c|c|}
\hline Authors & Sample & Methodological procedures \\
\hline 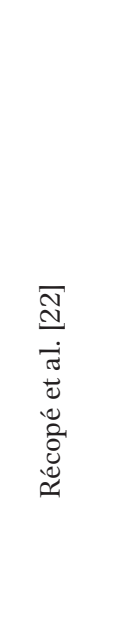 & $\begin{array}{l}\text { Two cases studies: } \\
\text { Case } 1 \text { : } \\
31 \text { professional male } \\
\text { volleyball players } \\
\text { from national teams } \\
\text { were observed during } \\
3 \text { matches in the } \\
\text { World League } \\
\text { Case } 2 \text { : } \\
12 \text { players } \\
\text { (6 from population A, } \\
\text { comprising } 3 \text { members } \\
\text { of each national team, } \\
\text { and } 6 \text { of population B, } \\
\text { comprising } 3 \text { members } \\
\text { of each national team) }\end{array}$ & $\begin{array}{l}\text { Case 1: } \\
\text { Systematic observation } \\
\text { of the players' behaviour } \\
\text { in specific defensive } \\
\text { scenarios } \\
\text { Case } 2 \text { : } \\
\text { Two types of qualitative data } \\
\text { were collected through the } \\
\text { results of case } 1 \text {. Performed } \\
\text { audio-visual recordings of } \\
\text { the } 12 \text { players' activity with } \\
\text { focus on relevant extracts of } \\
\text { film concerning their actions } \\
\text { during the selected defensive } \\
\text { situations identified from } \\
\text { case } 1\end{array}$ \\
\hline
\end{tabular}

Variables analysed

Case 1:

Behaviour and set of game situations: (1) characteristics of body posture; (2) characteristics of the player's

intervention; (3) result-based dissatisfaction reactions after losing a rally in defensive action

Case 2:

(1) relevant cues; (2) expectancies; (3) plausible goal;

(4) typical action

Main evidence

Cases 1 and 2:

The various components of activity are the contextual actualization, at various scenarios and in accordance with the current circumstances. The high time pressure, situation assessment, and course of action seem highly coupled,

but also organized and normed by this subconscious sense. If a subject has not enough time to consider several options before implementing one of them, the results lead to consider that this subconscious sense orients and organizes the individual activity (the situation assessment and the current action). Results lead to (1) an objectification and characterization of differences between 2 populations of elite volleyball players in a defensive context; (2) the identification, for each population, of a specific overall coherence that orients and organizes the defensive activity of its members

\begin{tabular}{|c|}
\hline $\begin{array}{l}5438 \text { rallies retrieved } \\
\text { from } 31 \text { matches of } \\
\text { volleyball }(121 \text { sets }) \\
\text { were sampled from } \\
2010 \text { Men's World } \\
\text { Championship and } \\
\text { Men's World League }\end{array}$ \\
\hline
\end{tabular}

An exhaustive Chi-square Automatic Interaction Detector growing method was applied as a visual and analytical multivariate decision support tool where the expected values of competing alternatives were calculated
Rally length, success of the team in the side-out phase, teams' ranking, and final action of the rally

Rallies between 8 and 10 seconds emerged as potential critical incidents of the game. These rallies seem to change the general trend in performance in accordance with the final action that finishes the rally. When the rally does not end with the first attack, the team in the serve phase can attack and has a greater chance to score. More than 10 -second rallies seem to balance success between teams

920 headers performed Nine match weeks were in 9 English Premier League of football of $2017-2018$ randomly selected. In each match week, one game was randomly selected. No team was included twice in the sample. Only the actions where a player intentionally contacted the ball were considered. Accidental touches were not coded
Game state, space of occupation, header location, set play type, number of opponent players, and the position of the player executing a header
Headers are game scenarios that have different moments and executions. A high occurrence of this scenario was used in long balls or even through crosses or throws, in order to avoid spatial progression of the attacking team. Almost half of the headers were executed during the set plays, especially on-goal kicks and throws. A considerable number of headers were executed in the centre of the penalty. Central defenders executed many interceptions and clearances of crosses, while forwards often used their heads to pass the ball

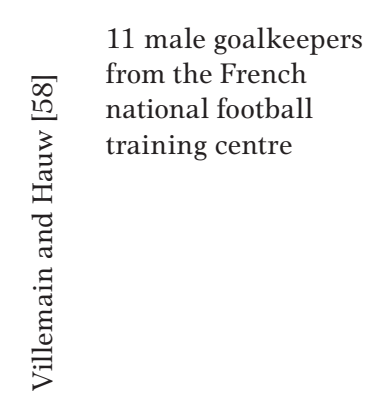

2 steps in data collection: (1) identification of typical critical game situations; (2) description of each critical situation through interviews (questioning interview). Questions were formulated by using present tense, brief sentences, and verbs of action
Five categories related to critical scenarios: (1) main topic; (2) actions (means to achieve goal); (3) attention contents (focus on perceptions); (4) background (knowledge mobilizes during the action); (5) inner states
23 critical game situations were ranked into 4 typical critical situations: coming off the line, goal-line clearances, one-onone, and diving were formulated as recurrent critical game situations for goalkeepers. Coming off the line represented the main critical game situation for all goalkeepers. Goal-line clearance and one-on-one were also mentioned as recurrent critical situations for 5 players. Diving was reported only twice as a critical situation 
the 2010 World Championship and men's World League, there were 5438 rallies in 31 games. The support tool used was the Chi-square Automatic Interaction Detector method, which allows a visual and analytical multivariate decision, where the expected values of competing alternatives were calculated. The variables considered in this study were the length of the rally, the success of the team in the side-out, the ranking of the teams, and the final action of the rally.

As main evidence, we highlight the rallies between 8 and 10 seconds that emerged as potential critical incidents of play, and these rallies changed the trend of performance in accordance with the final action of the rally. For example, when a rally does not end in the first side-out attack, it means that the team in possession of the service can attack and increase the chances of scoring. On the other hand, rallies with more than 10 seconds seem to balance the chances of success between both teams.

Sarajärvi et al. [57] studied the headers in high-performance football and characterized how they were executed in different game scenarios. The sample consisted of all headers made in 9 English Premier League, 920 headers of the 2017-2018 season. First, 9 weeks of play were randomly selected, and secondly, from each week of play, a game was selected for the study. Only actions in which a player intentionally contacted the ball were considered. The main evidence was as follows: (1) a high number of headers were executed to prevent the spatial progression of the attacking team, the method most used through long balls; (2) half of the headers were executed during the plays, especially on penalties and throws; (3) a considerable number of headers were executed near the penalty mark; (4) central defenders executed many interceptions of crosses, while forwards used their heads to pass the ball.

Finally, Villemain and Hauw [58] investigated the activity and performance of elite football goalkeepers in critical situations. Eleven male goalkeepers from the training centre of the French Football Federation were considered. Methodologically, they took 2 steps in data collection: the first one associated with the identification of typical game situations and the second one associated with the critical scenario.

Interviews were used to obtain the results, and each critical scenario resulted in an interview. Five categories related to critical scenarios were applied: main topic, actions (means to achieve the goal), attention contents, background, inner states. For each critical game scenario, attention focused on the specific moment defined by the player (start to the end of the ac- tion). Twenty three critical situations of the goalkeepers were recurrent, being classified in 4 critical scenarios: coming off the line, goal-line clearances, one-onone, and diving. Coming off the line represented the main critical game situation for all goalkeepers. The goal-line clearances and the one-on-one were referred to as recurrent critical situations for 5 of the 11 players. Diving was reported only twice as a critical situation.

\section{Risk of bias within and across studies}

All studies (Table 2) presented a low risk of bias arising from the randomization process. This agreement consisted in analysing the level of agreement of the answers, by using the kappa coefficient $(\kappa)$, revealing an agreement of $\kappa=1.0$. The agreement was high in all studies, with no divergence of responses.

\section{Discussion}

The analysis of critical game scenarios, in both critical and non-critical game moments, can theoretically provide an innovative perspective on match performance [23], helping to differentiate critical vs. noncritical scenarios and therefore providing more refined information for the coaches to act upon. The goal of this research was to systematically review studies focused on critical game scenarios in team sports and assess their findings. Four relevant databases (PubMed, SciELO, Scopus, and Web of Science) were searched, and an additional manual search was performed. Of the 279 articles identified, only 4 fit the eligibility criteria. Many of the excluded articles were duplicates, and numerous were theoretically driven works, but empirical studies on this topic were scarce.

In the 4 included articles, 4 common features can be highlighted: (i) they all address critical scenarios associated with game situations and the relevance of knowing how to perform under non-ideal game situations; (ii) these critical scenarios are usually, but not always, associated with time pressure and, consequently, game patterns present distinct features under these conditions in comparison with non-critical scenarios; (iii) overall, the literature on the topic and the framework of critical scenarios require further elaboration, systematization, and exploration; (iv) finally, all studies underlined how critical scenarios are crucial to understanding the development of game actions. Hence, a first finding was that research addressing the topic of critical scenarios is severely limited. Because critical scenarios reflect specific game situations and trigger activity in a cohesive structure [17] 
Table 2. Risk of bias in individual studies and across studies

\begin{tabular}{|c|c|c|c|c|c|c|c|c|}
\hline \multirow[b]{2}{*}{ Questions } & \multicolumn{4}{|c|}{ By main author } & \multicolumn{4}{|c|}{ By 2 co-authors } \\
\hline & 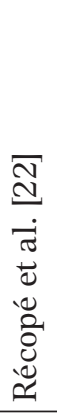 & 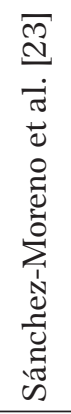 & 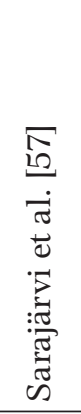 & 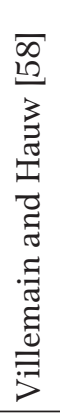 & 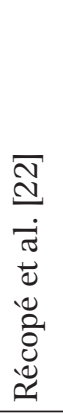 & 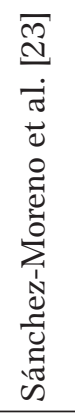 & 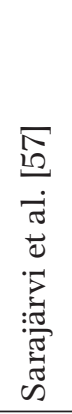 & 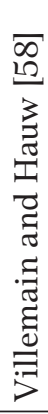 \\
\hline Was the study purpose stated clearly? & 1 & 1 & 1 & 1 & 1 & 1 & 1 & 1 \\
\hline Was relevant background literature reviewed? & 1 & 1 & 1 & 1 & 1 & 1 & 1 & 1 \\
\hline Was the design appropriate for the research question? & 1 & 1 & 1 & 1 & 1 & 1 & 1 & 1 \\
\hline Was the sample described in detail? & 1 & 1 & 1 & 1 & 1 & 1 & 1 & 1 \\
\hline Was the sample size justified? & 1 & 1 & 1 & 1 & 1 & 1 & 1 & 1 \\
\hline Was informed consent obtained? & 1 & NA & NA & 1 & 1 & NA & NA & 1 \\
\hline Were the outcome measures reliable? & 1 & 1 & 1 & 1 & 1 & 1 & 1 & 1 \\
\hline Were the outcome measures valid? & 1 & 1 & 1 & 1 & 1 & 1 & 1 & 1 \\
\hline Was the method described in detail? & 1 & 1 & 1 & 1 & 1 & 1 & 1 & 1 \\
\hline Were the results reported in terms of statistical significance? & 1 & 1 & 1 & 1 & 1 & 1 & 1 & 1 \\
\hline Where the analysis methods appropriate? & 1 & 1 & 1 & 1 & 1 & 1 & 1 & 1 \\
\hline Were conclusions appropriate given the study methods? & 1 & 1 & 1 & 1 & 1 & 1 & 1 & 1 \\
\hline $\begin{array}{l}\text { Are there any implications for practice given the results } \\
\text { of the study? }\end{array}$ & 1 & 1 & 1 & 1 & 1 & 1 & 1 & 1 \\
\hline $\begin{array}{l}\text { Were limitations of the study acknowledged and described } \\
\text { by the authors? }\end{array}$ & 1 & 1 & 1 & 1 & 1 & 1 & 1 & 1 \\
\hline
\end{tabular}

1-yes, 0 - no, NA - not applicable

that is likely very distinct from that in more regular, non-critical game scenarios, the observation indicates that this concept is being explored in a limited manner.

The study by Récopé et al. [22] linked game situations in volleyball to critical scenarios of the ball trajectories. From this study, we note that critical scenarios (which are representative of game actions at specific stages with instability in the environment) imposed by the unstable and variable temporal dynamics of the game appear to be important in sports games, including volleyball, where tempo is conditioned externally by regulation (giving greater predictability). As such, critical scenarios can serve as an important resource in training for increasing or decreasing pressure. Because time pressure allows players to deal with the pressures of the team's game system and thus to develop quick and efficient decision-making [7], it deserves further investigation by research. Moreover, critical scenarios have a time limit and this experience is central to the result of the action as these scenarios are emotionally charged, evolve the player, and allow a performance resulting from the processing of relevant information [61].
The studies by Villemain and Hauw [58] and Sarajärvi et al. [57] investigated actions in football that required high emotional control. The outcomes of these actions can directly dictate the game result. These studies focused on the actions to be performed in each scenario, the attention and experience of the players, and their emotions in critical scenarios [58]; and the state of the game, the location of the header, the number of opponents, and the position of the player at the time of the header [57]. These papers imply that the critical scenarios of the game have a component of great specificity as they help reinforce the importance of concentration and self-confidence, and thus progress the general idea that focus, attention, positioning, and presence are necessary for excellent performance [18].

A further aspect of critical game scenarios is that the regulation of independent structures influences the dynamic functionality of teams [12] to the extent that critical game scenarios can be differentiated on the basis of game style, team characteristics, game stages, and gameplay actions.

In this line, we highlight the clear relationship between critical scenarios, game phases, and gameplay 
[62] because these critical scenarios and their moments support research on risk situations (through rally length, team success, team ranking, and final action) aiming to improve adaptation to the various situations that occur in the game $[58,63]$. Thus, we note that critical scenarios have a strong positive influence on the evolution of teams and on the design of performance strategies [64]. Contrary to what was advocated in this review - that critical scenarios play a key role in sports games - Villemain and Hauw [58] suggested, after a focus on several critical scenarios, that this is not always the case. While many critical scenarios influence game outcomes, others have little impact. The environment of critical scenarios allows players to use informational restrictions to regulate their actions, on the basis of the team's decision, to influence their opponents behaviour [65]. Therefore, critical scenarios are central to understanding teams' perceptions. It is complex and difficult to define environment and players' perspectives as main actors of the game may provide deeper information for their study, with players describing their experience and action in each critical scenario in the header and loss of the ball $[57,58]$. Thus, research on critical scenarios can be expanded to include other, less-studied issues, such as their association with cognitive flow [66], which allows athletes to think and make decisions based on the variables involved and not just spontaneously.

The studies included in the final sample support the assumption that it is necessary to focus on critical scenarios to help clarify which game situations should and should not be considered as critical. Indeed, the 4 studies included in this systematic review can be considered pioneering research as they represent the only systematic investigations of critical scenarios and provide important research avenues for the future. The main findings support the idea that critical scenarios correspond to the representation of game contexts, at a certain stage of play, occurring in great complexity and with extreme emotional conditions. As such, we highlight the need to specify the definition of critical game scenarios and its associated terminology to avoid incorrect usage of the concept. It is noteworthy that because the number of eligible studies on critical scenarios was small, we subsequently reviewed non-experimental research; however, no more articles were considered.

\section{Conclusions}

The results of the systematic review show that critical scenarios have been neglected and largely unex- plored in research. Further studies on this topic are necessary because: (a) terminology in the available literature suggests that scenarios have been studied, but research specifically investigating critical scenarios is scarce; (b) a substantial body of work exists that misuses constructs and concepts, often incorrectly defining non-critical situations as being critical; (c) critical scenarios allow a systematic evolution of teams and a better knowledge of the game; (d) teams deal with time pressure and make faster and more efficient decisions; (e) critical scenarios can have 3 features that are essential for better individual and collective performance; (f) critical scenarios can be influenced by independent structures that help team dynamics; and (g) in critical scenarios, there can be variation in the form of critical manifestations that will lead to different measures. The small number of articles shows that although critical scenarios are theoretically relevant, they remain largely uninvestigated, hence highlighting the need for further research. As such, future studies should focus on high-level critical scenarios, use specific game exercises, and, consequently, apply more high-level investigations, as well as adopt a multidimensional perspective through the frequency of scenarios.

\section{Disclosure statement}

No author has any financial interest or received any financial benefit from this research.

\section{Conflict of interest}

The authors state no conflict of interest.

\section{References}

1. Moriarty JP. Theorising scenario analysis to improve future perspective planning in tourism. J Sustain Tour. 2012;20(6):779-800; doi: 10.1080/09669582.2012.67 3619.

2. Spaniol MJ, Rowland NJ. Defining scenario. Futures Foresight Sci. 2019;1(1):e3; doi: 10.1002/ffo2.3.

3. Laporta L, Afonso J, Valongo B, Mesquita I. Using social network analysis to assess play efficacy according to game patterns: a game-centred approach in high-level men's volleyball. Int J Perform Anal Sport. 2019;19(5): 866-877; doi: 10.1080/24748668.2019.1669007.

4. Hurst M, Loureiro M, Valongo B, Laporta L, Nikolaidis TP, Afonso J. Systemic mapping of high-level women's volleyball using social network analysis: the case of serve (K0), side-out (KI), side-out transition (KII) and transition (KIII). Int J Perform Anal Sport. 2016;16(2): 695-710; doi: 10.1080/24748668.2016.11868917.

5. Krane V, Joyce D, Rafeld J. Competitive anxiety, situation criticality and softball performance. Sport Psychol. 1994;8(1):58-72; doi: 10.1123/tsp.8.1.58. 
6. Ferreira A, Volossovitch A. Criticality and critical moments in sports games: a theoretical review [in Portuguese]. In: Volossovitch A, Ferreira A (ed.), Fundamentals and applications in game analysis [in Portuguese]. Lisbon: Edições FMH; 2013; 35-60.

7. Ritchie J, Basevitch I, Rodenberg R, Tenenbaum G. Situation criticality and basketball officials' stress levels. J Sports Sci. 2017;35(21):2080-2087; doi: 10.1080/ 02640414.2016 .1255770$.

8. Bar-Eli M, Tractinsky N. Criticality of game situations and decision making in basketball: an application of performance crisis perspective. Psychol Sport Exerc. 2000;1(1):27-39; doi: 10.1016/S1469-0292(00)00005-4.

9. García-Unanue J, Pérez-Gómez J, Giménez J-V, Felipe JL, Gómez-Pomares S, Gallardo L, et al. Influence of contextual variables and the pressure to keep category on physical match performance in soccer players. PLoS One. 2018;13(9):e0204256; doi: 10.1371/journal.pone.0204256.

10. Duarte R, Araújo D, Correia V, Davids K. Sports teams as superorganisms: implications of sociobiological models of behaviour for research and practice in team sports performance analysis. Sports Med. 2012;42(8):633642; doi: 10.2165/11632450-000000000-00000.

11. Vicsek T, Zafeiris A. Collective motion. Phys Rep. 2012; 517(3-4):71-140; doi: 10.1016/j.physrep.2012.03.004.

12. Gonçalves B, Marcelino R, Torres-Ronda L, Torrents C, Sampaio J. Effects of emphasising opposition and cooperation on collective movement behaviour during football small-sided games. J Sports Sci. 2016;34(14): 1346-1354; doi: 10.1080/02640414.2016.1143111.

13. Batista J, Goncalves B, Sampaio J, Castro J, Abade E, Travassos B. The influence of coaches' instruction on technical actions, tactical behaviour, and external workload in football small-sided games. Monten J Sports Sci Med. 2019;8(1):29-36; doi: 10.26773/mjssm.190305.

14. Nesti M, Littlewood M, O’Halloran L, Eubank M, Richardson D. Critical moments in elite premiership football: who do you think you are? Phys Cult Sport Stud Res. 2012;56(1):23-32; doi: 10.2478/v10141-012-0027-y.

15. Debanne T, Laffaye G, Trouilloud D. Motivational orientations and performance in penalty throws during elite male team handball games. Scand J Med Sci Sports. 2018;28(3):1288-1294; doi: 10.1111/sms.12995.

16. Stein M, Häußler J, Jäckle D, Janetzko H, Schreck T, Keim DA. Visual soccer analytics: understanding the characteristics of collective team movement based on feature-driven analysis and abstraction. Int J Geo-Inf. 2015;4(4):2159-2184; doi: 10.3390/ijgi4042159.

17. Bedny GZ, Karwowski W. Activity theory as a basis for the study of work. Ergonomics. 2004;47(2):134-153; doi: 10.1080/00140130310001617921.

18. Clark A. Being there: putting brain, body, and world together again. Cambridge: MIT Press; 1997.

19. Robbins P, Aydede M (eds.). The Cambridge handbook on situated cognition. Cambridge: Cambridge University Press; 2009.
20. Phatak A, Gruber M. Keep your head up - correlation between visual exploration frequency, passing percentage and turnover rate in elite football midfielders. Sports. 2019;7(6):139; doi: 10.3390/sports7060139.

21. Lupo C, Tessitore A. How important is the final outcome to interpret match analysis data: the influence of scoring a goal, and difference between close and balance games in elite soccer: comment on Lago-Penas and Gomez-Lopez (2014). Percept Mot Skills. 2016;122(1): 280-285; doi: 10.1177/0031512515626629.

22. Récopé M, Fache H, Beaujouan J, Coutarel F, Rix-Lièvre G. A study of the individual activity of professional volleyball players: situation assessment and sensemaking under time pressure. Appl Ergon. 2019;80: 226-237; doi: 10.1016/j.apergo.2018.07.003.

23. Sánchez-Moreno J, Mesquita I, Afonso J, Millán-Sánchez A, Ureña A. Effect of the rally length on performance according to the final action and the playing level in high-level men's volleyball. Rev Int Cienc Deporte. 2018;14(52):136-147; doi: 10.5232/ricyde2018. 05204.

24. Newell KM. Constraints on the development of coordination. In: Wade MG, Whiting HTA (eds.), Motor development in children: aspects of coordination and control. Dordrecht: Martinus Nijhoff Publishers; 1986; 341-360.

25. Araújo D, Silva P, Davids K. Capturing group tactical behaviors in expert team players. In: Baker JDF (ed.), Routledge handbook of sport expertise. New York: Routledge; 2019; 209-220.

26. Gómez M-Á, García-de-Alcaráz A, Furley P. Analysis of contextual-related variables on serve and receiving performances in elite men's and women's table tennis players. Int J Perform Anal Sport. 2017;17(6):919-933; doi: 10.1080/24748668.2017.1407208.

27. Andrienko G, Andrienko N, Budziak G, Dykes J, Fuchs G, von Landesberger T, et al. Visual analysis of pressure in football. Data Min Knowl Discov. 2017;31: 1793-1839; doi: 10.1007/s10618-017-0513-2.

28. Bartlett R, Button C, Robins M, Dutt-Mazumder A, Kennedy G. Analysing team coordination patterns from player movement trajectories in soccer: methodological considerations. Int J Perform Anal Sport. 2012;12(2): 398-424; doi: 10.1080/24748668.2012.11868607.

29. Blomqvist MT, Luhtanen P, Laakso L, Keskinen E. Validation of a video-based game-understanding test procedure in badminton. J Teach Phys Educ. 2000; 19(3):325-337; doi: 10.1123/jtpe.19.3.325.

30. Evans DJ, Whipp P, Lay BS. Knowledge representation and pattern recognition skills of elite adult and youth soccer players. Int J Perform Anal Sport. 2012;12(1): 208-221; doi: 10.1080/24748668.2012.11868594.

31. Rojas Ferrer CD, Shishido H, Kitahara I, Kameda Y. Read-the-game: system for skill-based visual exploratory activity assessment with a full body virtual realitysoccersimulation. PLoS One. 2020;15(3):e0230042; doi: 10.1371/journal.pone.0230042. 
J.B. Martins et al., Critical scenarios in team sports

32. Filipcic A, Leskosek B, Filipcic T. Split-step timing of professional and junior tennis players. J Hum Kinet. 2017;55(1):97-105; doi: 10.1515/hukin-2017-0009.

33. French KE, Nevett ME, Spurgeon JH, Graham KC, Rink JE, McPherson SL. Knowledge representation and problem solution in expert and novice youth baseball players. Res Q Exerc Sport. 1996;67(4):386-395; doi: 10.1080/02701367.1996.10607970.

34. González-Víllora S, García-López LM, Contreras-Jordán OR. Decision making and skill development in youth football players. Rev Int Med Cienc Act Fis Deporte. 2015;15(59):467-487; doi: 10.15366/rimcafd 2015.59.005.

35. Klostermann A, Panchuk D, Farrow D. Perception-action coupling in complex game play: exploring the quiet eye in contested basketball jump shots. J Sports Sci. 2018;36(9):1054-1060; doi: 10.1080/02640414.2017. 1355063.

36. Kokoulina OP, Tatarova SY, Averyasov VV, Kruglova YV. Skills-specific competitive timeframes in rugby sport. Theory Pract Phys Cult. 2018;8:80-82.

37. Koo DH, Panday SB, Xu DY, Lee CY, Kim HY. Logistic regression of wins and losses in Asia League Ice Hockey in the 2014-2015 season. Int J Perform Anal Sport. 2016;16(3):871-880; doi: 10.1080/24748668.2016.11 868935 .

38. Lupo C, Capranica L, Cugliari G, Gomez MA, Tessitore A. Tactical, swimming activity and heart rate aspects of youth water polo game. J Sports Med Phys Fitness. 2016;56(9):997-1006.

39. McPherson SL. Tactical differences in problem representations and solutions in collegiate varsity and beginner female tennis players. Res Q Exerc Sport. 1999;70(4): 369-384; doi: 10.1080/02701367.1999.10608057.

40. Praça GM, Alves Costa CL, Falconi Costa F, Pereira de Andrade AG, Chagas MH, Greco JP. Tactical behavior in soccer small-sided games: influence of tactical knowledge and numerical superiority. J Phys Educ. 2016;27(1): e2736; doi: 10.4025/jphyseduc.v27i1.2736.

41. Schläppi-Lienhard O, Hossner E-J. Decision making in beach volleyball defense: crucial factors derived from interviews with top-level experts. Psychol Sport Exerc. 2015;16(Pt 1):60-73; doi: 10.1016/j.psychsport.2014. 07.005 .

42. Sevil Serrano J, Práxedes Pizarro A, García-González L, Moreno Domínguez A, del Villar Álvarez F. Evolution of tactical behavior of soccer players across their development. Int J Perform Anal Sport. 2017;17(6):885901; doi: 10.1080/24748668.2017.1406781.

43. Uljevic O, Esco MR, Sekulic D. Reliability, validity, and applicability of isolated and combined sport-specific tests of conditioning capacities in top-level junior water polo athletes. J Strength Cond Res. 2014;28(6): 1595-1605; doi: 10.1519/JSC.0000000000000308.

44. Zubillaga A, Gabbett TJ, Fradua L, Ruiz-Ruiz C, Caro Ó, Ervilla R. Influence of ball position on playing space in Spanish elite women's football match-play. Int J Sports
Sci Coach. 2013;8(4):713-722; doi: 10.1260/1747-9541. 8.4.713.

45. Cañadas M, Solbes C, Feu S. Analysis of training tasks regarding game stages and situations in $\mathrm{U}^{\prime} 10$ and $\mathrm{U}^{\prime} 13$ categories. Rev Psicol Deporte. 2015;24(Suppl. 1):13-15.

46. Connor JD, Farrow D, Renshaw I. Emergence of skilled behaviors in professional, amateur and junior cricket batsmen during a representative training scenario. Front Psychol.2018;9:2012; doi: 10.3389/fpsyg.2018.02012.

47. Ferraz R, Gonçalves B, Van Den Tillaar R, Jiménez Sáiz S, Sampaio J, Marques MC. Effects of knowing the task duration on players' pacing patterns during soccer small-sided games. J Sports Sci. 2018;36(1): 116-122; doi: 10.1080/24733938.2017.1283433.

48. Gomez MA, Gasperi L, Lupo C. Performance analysis of game dynamics during the $4^{\text {th }}$ game quarter of NBA close games. Int J Perform Anal Sport. 2016;16(1):249263; doi: 10.1080/24748668.2016.11868884.

49. Gonçalves B, Folgado H, Coutinho D, Marcelino R, Wong D, Leite N, et al. Changes in effective playing space when considering sub-groups of 3 to 10 players in professional soccer matches. J Hum Kinet. 2018;62(1): 145-155; doi: 10.1515/hukin-2017-0166.

50. Lupo C, Condello G, Tessitore A. Notational analysis of elite men's water polo related to specific margins of victory. J Sports Sci Med. 2012;11(3):516-525.

51. Millslagle DG. Recognition accuracy by experienced men and women players of basketball. Percept Mot Skills. 2002;95(1):163-172; doi: 10.2466/pms.2002. 95.1.163.

52. Ramos A, Coutinho P, Silva P, Davids K, Mesquita I. How players exploit variability and regularity of game actions in female volleyball teams. Eur J Sport Sci. 2017;17(4):473-481; doi: 10.1080/17461391.2016.127 1459.

53. Ferreira AP, Volossovitch A, Sampaio J. Towards the game critical moments in basketball: a grounded theory approach. Int J Perform Anal Sport. 2014;14(2):428442; doi: 10.1080/24748668.2014.11868732.

54. Medina JÁ, Lorente VM, San José JR, Jiménez MA. Critical moments of the match in the best European football leagues [in Spanish]. Retos. 2020;38:77-82; doi: 10.47197/retos.v38i38.73001.

55. Reina M, Mancha D, Feu S, Ibáñez SJ. Is training carried out the same as competition? Analysis of load in women's basketball [in Spanish]. Rev Psicol Deporte. 2017;26(Suppl. 1):9-13.

56. Pombo Menezes R, Baldy dos Reis HH. Defensive performance against different offensive systems in handball: analysis of technical-tactical scenario and reflections on teaching [in Portuguese]. Rev Bras Cienc Esporte. 2017;39(2):168-175; doi: 10.1016/j.rbce.2017.02.003.

57. Sarajärvi J, Volossovitch A, Almeida CH. Analysis of headers in high-performance football: evidence from the English Premier League. Int J Perform Anal Sport. 2020;20(2):189-205; doi: 10.1080/24748668.2020. 1736409 . 
58. Villemain A, Hauw D. A situated analysis of football goalkeepers' experiences in critical game situations. Percept Mot Skills. 2014;119(3):811-824; doi: 10.2466/ 25.30.PMS.119c30z0.

59. Clemente FM, Afonso J, Castillo D, Los Arcos A, Silva AF, Sarmento H. The effects of small-sided soccer games on tactical behavior and collective dynamics: a systematic review. Chaos Solit Fractals. 2020;134:109710; doi: 10.1016/j.chaos.2020.109710.

60. Sarmento H, Marcelino R, Anguera MT, Campaniço J, Matos N, Leitão JC. Match analysis in football: a systematic review. J Sports Sci. 2014;32(20):1831-1843; doi: 10.1080/02640414.2014.898852.

61. Williams AM, Davids K. Visual search strategy, selective attention, and expertise in soccer. Res Q Exerc Sport. 1998;69(2):111-128; doi: 10.1080/02701367.1998.106 07677.

62. Sánchez-Moreno J, Marcelino R, Mesquita I, Ureña A. Analysis of the rally length as a critical incident of the game in elite male volleyball. Int J Perform Anal Sport. 2015;15(2):620-631; doi: 10.1080/24748668.2015.11 868819 .

63. Atance CM, O’Neill DK. The emergence of episodic future thinking in humans. Learn Motiv. 2005;36(2):126144; doi: 10.1016/j.lmot.2005.02.003.

64. Duarte R, Araújo D, Freire L, Folgado H, Fernandes O, Davids K. Intra- and inter-group coordination patterns reveal collective behaviors of football players near the scoring zone. Hum Mov Sci. 2012;31(6):1639-1651; doi: 10.1016/j.humov.2012.03.001.

65. Evans MB, Eys MA. Collective goals and shared tasks: interdependence structure and perceptions of individual sport team environments. Scand J Med Sci Sports. 2015;25(1):e139-e148; doi: 10.1111/sms.12235.

66. Neville TJ, Salmon PM. Never blame the umpire a review of situation awareness models and methods for examining the performance of officials in sport. Ergonomics. 2016;59(7):962-975; doi: 10.1080/0014 0139.2015.1100758. 